\title{
Protective Effects of Thunbergia laurifolia (Linn.) on Organophosphorous (chlorpyrifos)-Induced Cholinesterase Dysfunction
}

\author{
Malatee TAYEH ${ }^{1}$, Jirapat NAWARAT ${ }^{2}$, \\ Moe Pwint PHYU ${ }^{3}$ and Jitbanjong TANGPONG ${ }^{1,3, *}$ \\ ${ }^{1}$ Division of Medical Technology, School of Allied Health Sciences, Walailak University, \\ Nakhon Si Thammarat 80161, Thailand \\ ${ }^{2}$ Division of Physical Therapy, School of Allied Health Sciences, Walailak University, \\ Nakhon Si Thammarat 80161, Thailand \\ ${ }^{3}$ Division of Biomedical Sciences, School of Allied Health Sciences, Walailak University, \\ Nakhon Si Thammarat 80161, Thailand
}

('Corresponding author’s e-mail: njibjoy@yahoo.com)

Received: 30 March 2017, Revised: 10 October 2017, Accepted: 20 November 2017

\begin{abstract}
Organophosphorous (chlorpyrifos) has been widely used in pest control. It is considered to be a functionally irreversible inhibitor of cholinesterase $(\mathrm{ChE})$, since the time necessary to liberate the enzyme from inhibition may be in excess of time required for the synthesis of new ChE. This study was designed to investigate the effects of total phenolic content, total antioxidant capacity, and free radical scavenging activities in a cell free system present in Thunbergia laurifolia (Linn.) (TL) and further examine their ability against chlorpyrifos-induced ChE dysfunction in vitro (blood and brain of mice) studies. The results showed that TL has the highest phenolic content, which is a significant positive correlation with its antioxidant activity $\left(R^{2}=0.99\right)$. Additionally, the effects of $50 \%$ inhibitory concentration of TL on scavenging free radical activities $\left(\mathrm{IC}_{50}\right)$ for hydroxyl, superoxide, hydrogen peroxide radical and nitric oxide in the cell free system were $1.47 \pm 0.02,2.23 \pm 0.08,1.66 \pm 0.09$ and $1.00 \pm 0.07 \mathrm{mg} / \mathrm{mL}$, respectively. We found TL showed a potential inhibition of chlorpyrifos-induced $\mathrm{ChE}$ dysfunction in a concentration dependent manner. These data suggest that TL exhibits anti-oxidant and, at least in part, neuroprotective properties against chlorpyrifos-induced $\mathrm{ChE}$ alteration. We strongly believe that these antioxidant constituents are prospective novel nutriceuticals.
\end{abstract}

Keywords: Organophosphorous (chlorpyrifos), cholinesterase (ChE), Thumbergia laurifolia (Linn) (TL), free radical scavenging

\section{Introduction}

Organophosphate (OP) insecticides, lubricants, and plasticizers present potential health and safety hazards to individuals, associated with their manufacture, formulation, application, and field use [1,2]. Organophosphate, when used as an insecticide, inhibits mainly cholinesterase (ChE), the enzyme responsible for degradation of neurotransmitter acetylcholine (ACh). Accumulation of acetylcholine $(\mathrm{ACh})$ at the synapses results in excessive stimulation of cholinergic receptors in postsynaptic cells, leading to cholinergic toxicity [3]. In addition to neurotoxicity, the adverse effects of OP exposure may alter other body functions. The ability of OP pesticides to interfere with the immune system and exert immunotoxic effects, through both anti-cholinergic and non-cholinergic methods, has been recognized in recent years [4]. Organophosphates have become the most widely used pesticides since the removal of organochlorine pesticide from use. Consequently, non-target species, including humans working as 
occupational workers in roles such as insecticide formulators and farm workers, are frequently affected by organophosphates. The inhibition of $\mathrm{ChE}$ is generally regarded as a standard biochemical marker and a mainstay for the fast initial screening of organophosphate and carbamate toxicity [5]. Many studies have shown that oxidative stress may be induced in humans and animals during acute OP exposure alongside the characteristic inhibition of $\mathrm{ChE}[6,7]$. Further, it is evident that antioxidant-rich plant extracts offer protection against $\mathrm{OP}$-induced neurotoxicity, as evident from reduced $\mathrm{ChE}$ inhibition [8].

Plants, rich in antioxidants including polyphenolic compounds, tocophenols, and carotenoids, are able to retard the progress of many oxidative stress related chronic diseases in humans. Therefore, antioxidant compounds are potential novel nutriceuticals, due to their role in protecting the body from oxidative stress and nitrosative stress, and are derived either from normal metabolic processes or from external sources [9]. Thunbergia laurifolia (Linn) (TL) is a Thai medicinal plant known for its antimutagenic, anti-inflammatory, and anti-pyretic properties [10,11]. Tangpong and Satarug stated that TL leaf extract reduced $\mathrm{Pb}$ uptake-induced neuronal cell death and memory loss in mice; the anti-oxidant activities of the TL leaf extract might account for these effects [12].

This study aimed to determine the total phenolic content and scavenging properties of the Thai traditional medicinal plant TL against organophosphate (chlorpyrifos)-induced ChE dysfunction in vitro (blood and brain of ICR mice) studies. From this perspective, and considering the powerful effects present, the assessment of dietary antioxidants from traditional plants can reduce/prevent chlorpyrifos exposure-induced $\mathrm{ChE}$ inhibition.

\section{Materials and methods}

Chemicals and preparation of Thunbergia laurifolia (Linn.) aqueous extract

Chlorpyrifos (0-0 diethyl 0-3, 5, 6- trichloro-2-pyridyl), and all chemicals, were purchased from Sigma-Aldrich, St. Louis, MO, USA. TL leaves were collected during April-May from Nakhon Si Thammarat, Thailand. Leaves were air dried and ground in a blender to a fine powder. TL leaf powder, $100 \mathrm{~g}$, was extracted with $1,000 \mathrm{~mL}$ of boiling water for $15 \mathrm{~min}$. The TL leaf aqueous extracts were filtered by Whatman No.1 and then lyophilized using a freeze dryer at $-20{ }^{\circ} \mathrm{C}$ for $20 \mathrm{~h}$ (Eyela, Tokyo, Japan). The powder was stored at $20^{\circ} \mathrm{C}$ until it was used. Chlorpyrifos aqueous stock solution was freshly prepared in distilled water prior to use.

Total phenolic content and total antioxidant capacity of Thunbergia laurifolia (Linn.) aqueous extract

The total phenolic content of the extracts was measured according to the Folin-Ciocalteu method [13]. The concentrations of phenolic content in the TL extracts were expressed as gallic acid equivalents (GAEs). Briefly, $12.5 \mu \mathrm{L}$ of extract of different concentrations $(0.1,0.25,0.5$, and $1 \mathrm{mg} / \mathrm{mL})$ and control (distilled water was used instead of extract) were added to a 96-well microplate. Then, $12.5 \mu \mathrm{L}$ of FolinCiocalteu's phenol reagent was added to each well. After $5 \mathrm{~min}, 125 \mu \mathrm{L}$ of saturated sodium carbonate $\left(\mathrm{Na}_{2} \mathrm{CO}_{3}\right)$ solution $(\sim 7.5 \%)$ was added to the mixture. The reaction mixtures were incubated at room temperature for $30 \mathrm{~min}$. Distilled water was used as a blank. All assays were conducted in triplicate. The absorbance was determined at $765 \mathrm{~nm}$ with a microplate reader. Gallic acid solutions with concentrations ranging from 0 to $100 \mathrm{mg} / \mathrm{L}$ were used for calibration. A dose response linear regression was generated by using the gallic acid standard absorbance, and the levels in the samples were expressed as gallic acid equivalents (mg of GAEs/mg dry weight).

2, 2'-azino-bis (3-ethylbenzothiazoline-6-sulphonic acid), or ABTS, also forms a relatively stable free radical, which decolorizes in its non-radical form. The analysis of $\mathrm{ABTS}^{+}$scavenging activity was determined according to the method of Rice-Evan et al. [14]. In this method, an antioxidant is added to a pre-formed ABTS radical solution and, after a fixed time period, the remaining $\mathrm{ABTS}^{0+}$ is quantified with a microplate reader at $734 \mathrm{~nm}$. $\mathrm{ABTS}^{0+}$ was produced by reacting $7 \mathrm{mM}$ ABTS in $\mathrm{H}_{2} \mathrm{O}$ with $4.9 \mathrm{mM}$ potassium persulfate $\left(\mathrm{K}_{2} \mathrm{~S}_{2} \mathrm{O}_{8}\right)$ and stored in the dark at room temperature for $12-18 \mathrm{~h}$. The ABTS $^{0+}$ solution was diluted to give an absorbance of $0.750 \pm 0.025$ at $734 \mathrm{~nm}$. Then, $180 \mu \mathrm{L}$ of $\mathrm{ABTS}^{0+}$ solution was added to $20 \mu \mathrm{L}$ of TL solution in distilled water at different concentrations $(0.1-1 \mathrm{mg} / \mathrm{mL})$. The 
absorbance was recorded 3 min after mixing, and the percentage of radical scavenging was calculated for each concentration relative to a blank containing no scavenger. The extent of decolorization was calculated as percentage reduction of absorbance. For preparation of a standard curve, different concentrations of trolox were used and expressed in millimole of trolox equivalent per gram of dry weight (mM TEAC/g dw).

The correlation coefficients $\left(R^{2}\right)$ of the total antioxidant capacity and the total phenolic content of TL aqueous leaf extract were considered.

\section{Hydroxyl radical assay}

Hydroxyl radical assay was performed according to the Fenton-type reaction [15]. The reaction mixture contained $1 \mathrm{~mL}$ of $0.1 \mathrm{mM}$ methyl violet, $0.5 \mathrm{~mL}$ of $5 \mathrm{mM} \mathrm{FeSO}_{4}, 0.5 \mathrm{~mL}$ of $1 \% \mathrm{H}_{2} \mathrm{O}_{2}$, and $2 \mathrm{~mL}$ of Tris buffer ( $\mathrm{pH} 4.0) .10 \mathrm{~mL}$ and $0.5 \mathrm{~mL}$ of extract (TL) were then added. The absorbance of the reaction mixture was measured at $565 \mathrm{~nm}$ using a spectrophotometer. The scavenging activity (D) of the sample on hydroxyl radicals was calculated according to the following formula;

D-[As-A0/A-A0] $\times 100 \%$

$\mathrm{DC}_{50}$ is defined as the concentration of sample required to scavenge $50 \%$ of ROS.

\section{Superoxide anion assay}

One hundred $\mu \mathrm{L}$ of $3 \mathrm{mM}$ pyrogallol and $3 \mathrm{~mL}$ of Tris buffer $(\mathrm{pH} 8.2)$ was mixed with $0.5 \mathrm{~mL}$ of the sample at $10 \mathrm{mg} / \mathrm{Ml}$, and the auto-oxidation rate of pyrogallol was measured by determining the changes in the absorbance at $325 \mathrm{~nm}$ in 4 min using a UV-Vis spectrophotometer. The scavenging activities (D) of the sample on superoxide anion was calculated by comparing DA1/min (without sample) and DA2/min (with sample) of the pyrogallol system, according to the following formula [15];

$\mathrm{D}=[\Delta \mathrm{A} 1-\Delta \mathrm{A} 2 / \Delta \mathrm{A} 1] \times 100 \%$

\section{Nitric oxide scavenging capacity assay}

The compound sodium nitroprusside is known to decompose in aqueous solution at physiological $\mathrm{pH}$ (7.2), producing $\mathrm{NO}^{\circ}$. Under aerobic conditions, $\mathrm{NO}^{\bullet}$ reacts with oxygen to produce stable products (nitrate and nitrite), which can be determined using Griess reagent. The absorbance of the chromophore that forms during diazotization of the nitrite with sulfanilamide and subsequent coupling with naphthyl ethylenediamine dihydrochloride can be immediately read at $550 \mathrm{~nm}$. $4 \mathrm{~mL}$ of extract or standard solutions of different concentrations were taken in different test tubes, and $1.0 \mathrm{~mL}$ of sodium nitroprusside $(5 \mathrm{mM})$ solution was added. They were then incubated for $2 \mathrm{~h}$ at $30{ }^{\circ} \mathrm{C}$ to complete the reaction. $2 \mathrm{~mL}$ solution was withdrawn from the mixture and mixed with $1.2 \mathrm{~mL}$ of Griess reagent $(1 \%$ Sulfanilamide, $0.1 \%$ naphthylethylene diamine dihydrochloride in $2 \% \mathrm{H}_{3} \mathrm{PO}_{4}$ ), and the absorbance of the solutions measured at $550 \mathrm{~nm}$ using a spectrophotometer against a blank [16]. Ascorbic acid was used as standard. The percentage (\%) inhibition activity was calculated from the following equation;

$[(\mathrm{A} 0-\mathrm{A} 1) / \mathrm{A} 0] \times 100$.

where A0 is the absorbance of the control, and A1 is the absorbance of the extract or standard. $\mathrm{IC}_{50}$ was calculated by the linear regression method.

\section{Hydrogen peroxide scavenging effects}

The ability of the extract to scavenge hydrogen peroxide was assessed by the method of Dan et al. [15]. A solution of $\mathrm{H}_{2} \mathrm{O}_{2}(40 \mathrm{mM})$ was prepared in phosphate buffer. Extracts (TL) at a concentration of $20 \mu \mathrm{L}$ were added to $\mathrm{H}_{2} \mathrm{O}_{2}$ solution $(80 \mu \mathrm{L})$, and the total volume was made up to $100 \mu \mathrm{L}$. The absorbance of the reaction mixture was recorded at $230 \mathrm{~nm}$ in a spectrophotometer. A blank solution, 
containing phosphate buffer without $\mathrm{H}_{2} \mathrm{O}_{2}$, was prepared. The extent of the $\mathrm{H}_{2} \mathrm{O}_{2}$ scavenging of the extracts (TL) was calculated;

$\%$ of scavenging of hydrogen peroxide $=[(\mathrm{A} 0-\mathrm{A} 1) / \mathrm{A} 0] \times 100$.

where A0 is the absorbance of the control, and A1 is the absorbance of the extract or standard.

\section{Determination of cholinesterase (ChE) activity}

The AChE and BChE assays were performed according to the colorimetric method $[17,18]$, using acetylthiocholine iodide and s-butyrylthiocholine iodide as substrates. For the enzyme source, mouse brains, red blood cells, and plasma samples were used to determine the activities. The rates of hydrolysis by $\mathrm{AChE}$ and BCHE were monitored spectrophotometrically. Each sample or standard solution $(500 \mu \mathrm{L})$ was mixed with an enzyme solution $(500 \mu \mathrm{L})$. After incubation at $37{ }^{\circ} \mathrm{C}$ for $15 \mathrm{~min}$, the absorbance was measured at $405 \mathrm{~nm}$ immediately after adding Ellman's reaction mixture $(3.5 \mathrm{ml} ; 0.5 \mathrm{mM}$ acetylthiocholine iodide, $1 \mathrm{mM}$ DTNB) or s-butyrylthiocholine iodide in a $50 \mathrm{mM}$ sodium phosphate buffer ( $\mathrm{pH} \mathrm{8.0)}$ to the above reaction mixture. Reading was repeated for $10 \mathrm{~min}$ at 2 min intervals to verify that the reaction occurred linearly. A blank reaction was measured by substituting saline for the enzyme.

\section{Statistical analysis}

Data were expressed as mean \pm SEM. The data obtained was analyzed using the Student- $t$ - test and one way ANOVA, which need to compare treatment groups. The $p$ values of $\leq 0.05$ were considered to identify statistically significant levels.

\section{Results and discussion}

Total phenolic content and antioxidant activity

Table 1 showed that TL aqueous leaf extract $(0,0.05,0.1,0.2 \mathrm{mg} / \mathrm{mL})$ contained total phenolic content and total antioxidant capacity. The correlation between the antioxidant activity and the total phenolic content was determined. The antioxidant capacity of the extract appears to be largely influenced by the content of the total phenolic compound $\left(R^{2}=0.996\right)$ (Figure 1).

Table 1 Total phenolic content and total antioxidant capacity of Thumbergia laurifolia (Linn.) aqueous leaf extract.

\begin{tabular}{ccc}
\hline $\begin{array}{c}\text { Concentration of } \\
\text { Thunbergia laurifolia (Linn.) } \\
\text { (mg/mL) }\end{array}$ & $\begin{array}{c}\text { Total Phenolic content } \\
\text { (mg GAE/mg dw) }\end{array}$ & $\begin{array}{c}\text { Total antioxidant capacity } \\
\text { (mM TEAC/g dw) }\end{array}$ \\
\hline 0.05 & $6.11 \pm 0.59$ & $206 \pm 11.84$ \\
0.1 & $10.12 \pm 0.34$ & $390 \pm 12.46$ \\
0.2 & $19.3 \pm 1.24$ & $694 \pm 11.84$ \\
\hline
\end{tabular}

Data are presented as mean $\pm \mathrm{SEM}, \mathrm{mgGAE} / \mathrm{mg} \mathrm{dw}$; milligram gallic acid equivalent per milligram dry weight, mM TEAC/g dw; millimolar trolox equivalent antioxidant capacity per gram dry weight. 


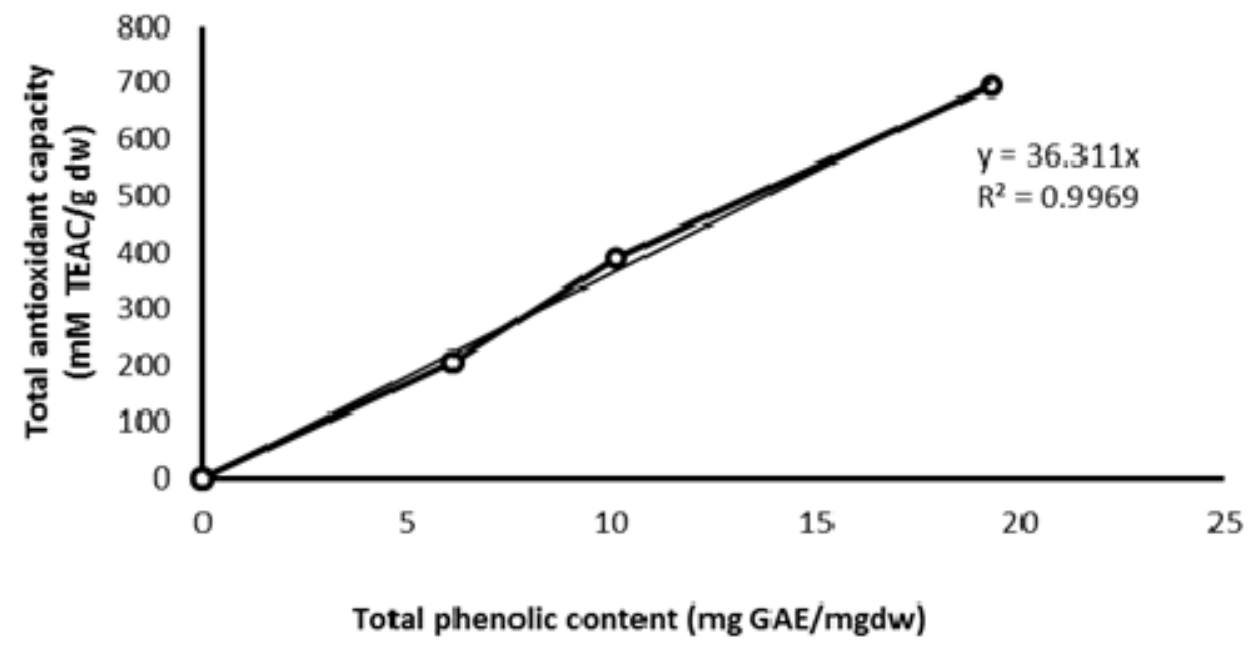

Figure 1 Linear correlation of trolox equivalent antioxidant capacity (mM TEAC/g dw, Y) versus the total phenolic content (mg GAE/mg dw, X) of Thunbergia laurifolia (Linn.) aqueous leaf extract.

\section{Radical scavenging activities in cell free system}

Table 2 provides a breakdown of selected extracts possessing antioxidant properties which could react with free radicals (hydroxyl, hydrogen peroxide, superoxide, and nitric oxide). In this study, the TL amounts obtained $(1.47,2.23,1.66$ and $1.0 \mathrm{mg} / \mathrm{mL})$ were the amounts of antioxidant material required to scavenge $50 \%$ of free radicals in the hydroxyl radical, superoxide, hydrogen peroxide, and nitric oxide scavenging assay. According to these results, TL aqueous extract showed all radical scavenging activities.

Table 2 Hydroxyl radical, superoxide anion, hydrogen peroxide, and nitric oxide scavenging assay in cell free system.

\begin{tabular}{lc}
\hline Free radical & $\begin{array}{c}\text { Thunbergia laurifolia (Linn.) } \\
\text { IC }_{\mathbf{5 0}} \pm \text { SEM (mg/mL) }\end{array}$ \\
\hline Hydroxyl radical & $1.47 \pm 0.02$ \\
Superoxide anion & $2.23 \pm 0.08$ \\
Hydrogen peroxide & $1.66 \pm 0.09$ \\
Nitric oxide & $1.0 \pm 0.07$ \\
\hline
\end{tabular}

Data are presented as mean $\pm \mathrm{SEM}$.

\section{Cholinesterase (ChE) in vitro test}

Organophosphates (chlorpyrifos) are widely used for pest control, and act primarily by inhibition of insect and mammalian ChE. Our findings are consistent with chlorpyrifos significantly inhibiting ChE activity $(p<0.05)$. An inhibition of more than $50 \%$ was observed at concentrations equal to, or higher than, $5 \mu \mathrm{g} / \mathrm{mL}$ (Figure 2). Chlorpyrifos at higher concentrations tested in vitro (5 and $20 \mu \mathrm{g} / \mathrm{mL}$ ) promoted significant decrease in ChE activity (1636 $\pm 10.39 \mathrm{U} / \mathrm{L})$ and $(620 \pm 12.45 \mathrm{U} / \mathrm{L})$, respectively. 
http://wjst.wu.ac.th

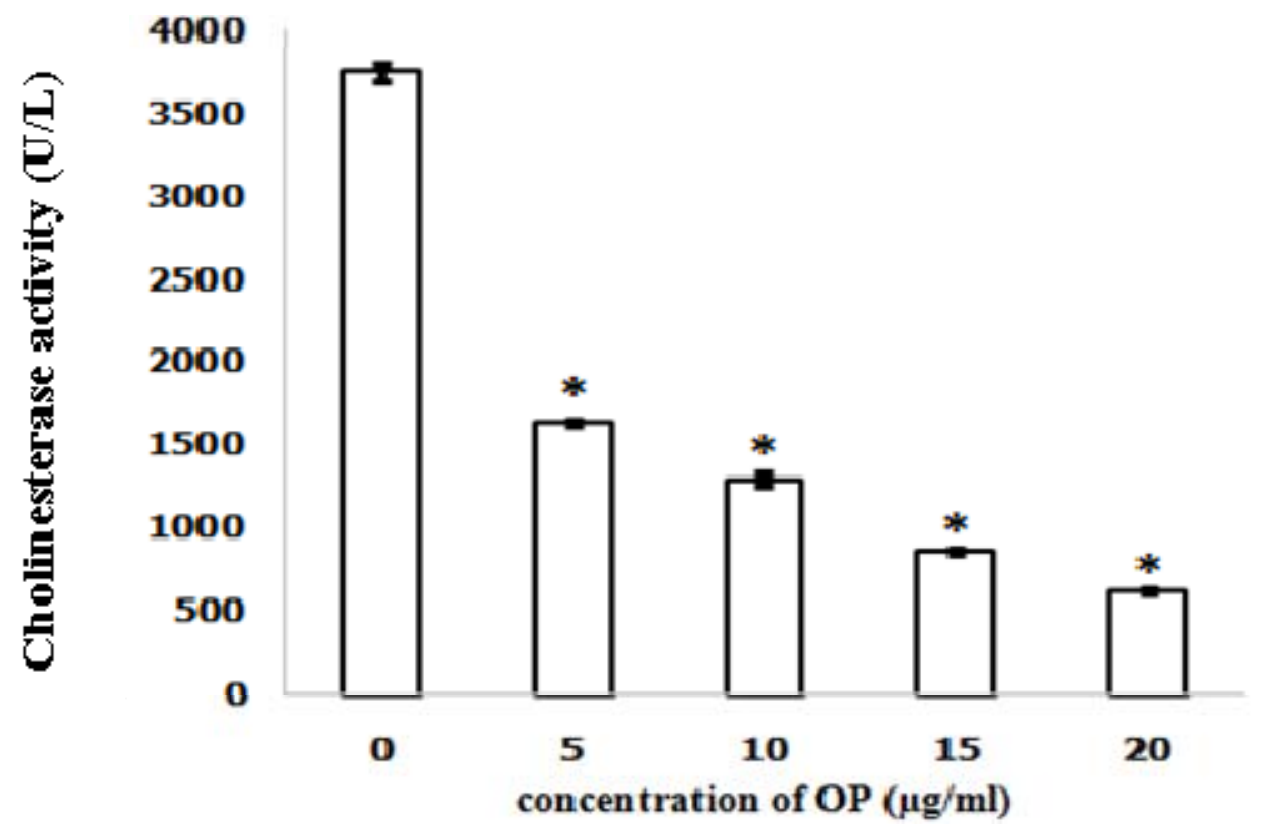

Figure 2 Organophosphate (OP)-inhibited cholinesterase (ChE) activity in vitro study. Data are presented as mean \pm SEM. $* p<0.05$, significant difference compared between untreated group and OP group.

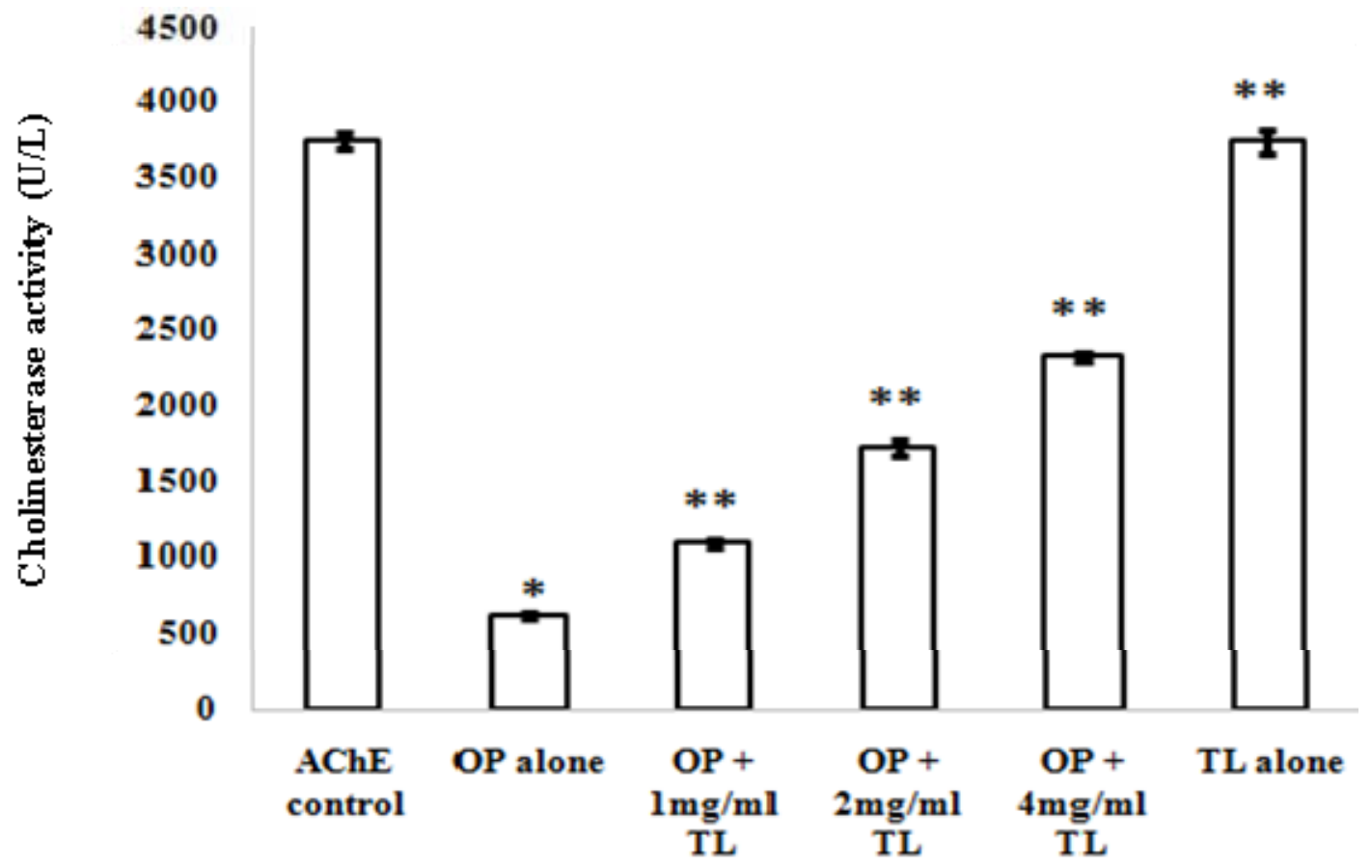

Figure 3 Protective effect of Thunbergia laurifolia (Linn.) against Organophosphate (OP)-induced cholinesterase $(\mathrm{ChE})$ activity in vitro study. Each value is expressed as mean $\pm \mathrm{SEM} .{ }^{*} p<0.05$, compared with the control group. ${ }^{* *} p<0.05$, versus OP treated group. 
In vitro effects of Thunbergia laurifolia (Linn.) aqueous extracts against organophosphorous (chlorpyrifos)-induced cholinesterase (ChE) activity

In order to determine whether the extract can attenuate neurotransmitter system damage, we measured the activities of $\mathrm{ChE}$. According to Figure 2, chlorpyrifos at higher concentrations tested in vitro studies promoted significant decreases in $\mathrm{ChE}$ activity. Interestingly, on the other hand, treatments with extracts restored the activities of $\operatorname{ChE}(p<0.05)$ (Figure 3). There was no significant difference in the activities of $\mathrm{ChE}$ between the control group and the extract-treated group.

Thunbergia laurifolia (Linn.) aqueous leaf extract protects cholinesterase activity in chlorpyrifos-treated mice brains and red blood cells

As shown in Figures $\mathbf{4}$ and 5, the activity of $\mathrm{ChE}$ was obviously decreased in mouse brains and red blood cells treated with chlorpyrifos, as compared with the controls $(p<0.05)$. However, there was significantly increase in the activities of $\mathrm{ChE}$ in the co-treatment of chlorpyrifos with $\mathrm{TL}$ aqueous leaf extract at $2 \mathrm{mg} / \mathrm{mL}$ or $4 \mathrm{mg} / \mathrm{mL}(p<0.05)$. There is no significant difference between the TL control group and the normal group.

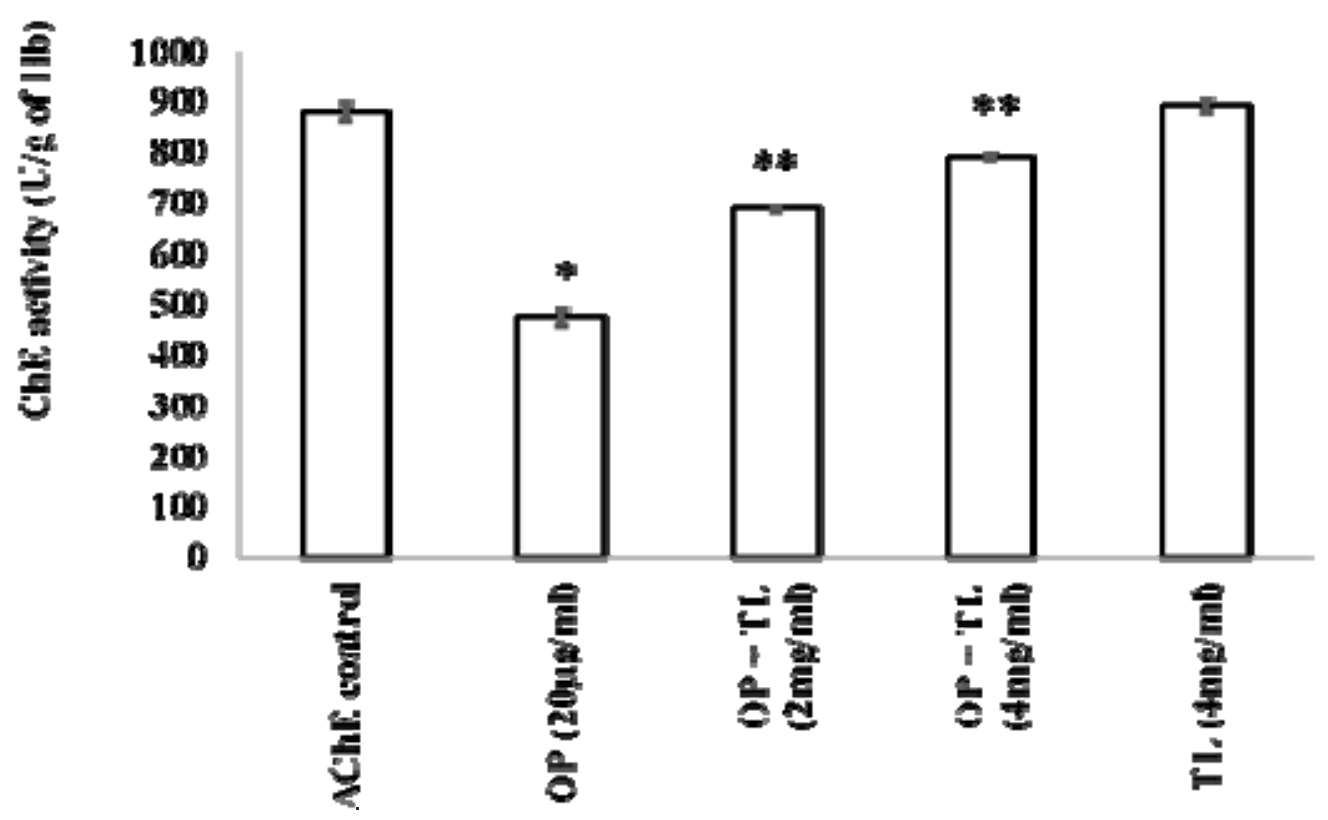

Figure 4 Protective effect of Thunbergia laurifolia (Linn.) against organophosphate (OP)-induced cholinesterase (ChE) activity in mouse red blood cells. Each value is expressed as mean \pm SEM. ${ }^{*} p<$ 0.05 , compared with the control group. ${ }^{* *} p<0.05$, versus OP treated group. 


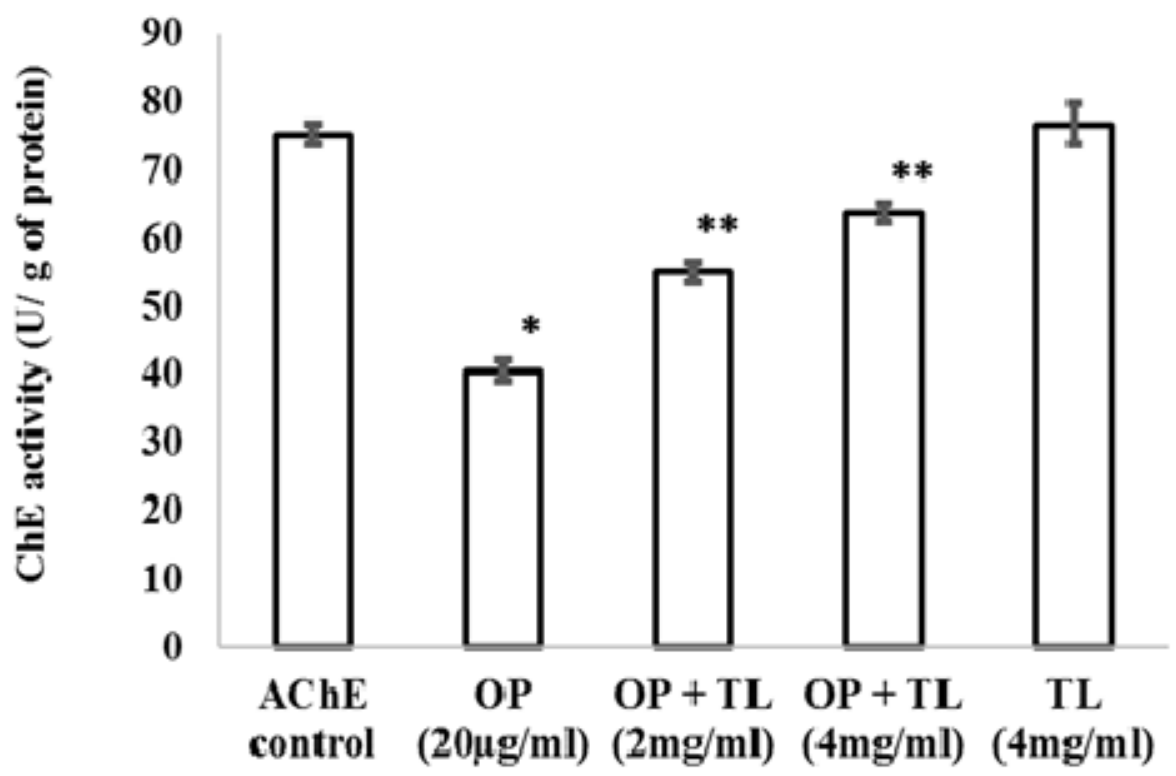

Figure 5 Protective effect of Thunbergia laurifolia (Linn.) against OP-induced cholinesterase (ChE) activity in mouse brains. Each value is expressed as mean \pm SEM. ${ }^{*} p<0.05$, compared with the control group. $* * p<0.05$, versus OP treated group.

\section{Discussions}

It is well known that phenolic compounds contribute to quality and nutritional value, in terms of modifying color, taste, aroma, and flavor, and also in providing health benefit effects. They also serve in plant defense mechanisms to counteract reactive oxygen species in order to survive, prevent molecular damage, and prevent disruption by microorganisms, insects, and herbivores [19]. However, the correlation between total phenolic content and antioxidant activity is not clear. Our results show that the correlation between the total phenolic content and the antioxidant activity of the extracts had correlation coefficients of $R^{2}=0.996,0.97,0.92$, and 0.84 . This suggests that the antioxidant capacity of the extracts results from the contribution of the phenolic compounds. They may also have metal chelating potential [20].

Superoxide radicals are generated by direct auto-oxidation of $\mathrm{O}_{2}$ during mitochondria electron transport reaction. $\mathrm{O}_{2} \bullet$ so formed is catabolized to produce $\mathrm{H}_{2} \mathrm{O}_{2}$ by superoxide dismutase (SOD), a metalloprotein enzyme. It is considered to be the least reactive type of ROS, and the most commonly produced free radical in humans [21]. However, it is normally formed first, and its effects can be magnified because it produces other kinds of free radicals and oxidizing agents. Hydrogen peroxide has strong oxidizing properties. It can be formed by many oxidizing enzyme, such as SOD, which can cross cellular membranes and may slowly oxidize a number of intracellular compounds. $\mathrm{H}_{2} \mathrm{O}_{2}$ is reduced to water enzymatically by catalase (in the peroxisomes) and by glutathione peroxidase (both in the cytosol and mitochondria). Hydrogen peroxide itself is not very reactive; however, it can sometimes be toxic to cells, because it may give rise to hydroxyl radical in them [22]. Hydroxyl radicals are the most reactive radical molecules, and can damage cell membranes and lipoproteins by lipid peroxidation. Reactive nitrogen species (RNS, e.g., nitric oxide, $\mathrm{NO}^{\circ}$ ) play a vital role in the generation of free radicals. $\mathrm{NO}^{\circ}$ is an abundant reactive radical which has a role in diverse physiological processes, such as neurotransmission, blood pressure regulation, defense mechanisms, smooth muscle relaxation, and immune regulation. Overproduction of reactive nitrogen species is called nitrosative stress [23]. Table 2 depicts the scavenging activities of the $\mathrm{TL}$ aqueous extract $\mathrm{IC}_{50}$, which shows antioxidant activities, 
proving its capacity to scavenge superoxide, hydrogen peroxide, and hydroxyl radical. TL also provided a breakdown, as selected extracts possess antioxidant properties which could react with free radicals (nitric oxide). In this study, TL $(1.0 \pm 0.07 \mathrm{mg} / \mathrm{mL})$ amounts were obtained, which were the amounts of antioxidant material required to scavenge $50 \%$ of free radicals in the nitric oxide scavenging assay system.

Organophosphorous (chlorpyrifos) (OP) is widely used for pest control, and acts primarily by inhibition of insect and mammalian ChE. OP pesticide has to be designed for enzyme ChE inhibition in a dose dependent manner at the neuromuscular junction in the central nervous system and peripheral nervous system [24]. Our findings are consistent with chlorpyrifos significantly inhibiting AChE activity in a concentration dependent manner. Many reports have indicated that OP compounds cause inhibition of $\mathrm{ChE}$, as well as induce oxidative stress marked by increased lipid peroxidation, altered antioxidant enzyme activities, and reduced glutathione [25,26]. According to the statistical analysis, significant in vitro inhibition was obtained from the lowest concentration tested. In vitro effects of TL extracts against chlorpyrifos-induced $\mathrm{ChE}$ dysfunction showed amelioration of chlorpyrifos-induced $\mathrm{ChE}$ inhibition by TL aqueous extracts, which could be due to the high antioxidant activity of its constituents. Green tea extract, which is rich in antioxidants, has been shown to protect against OP compound toxicity [27]; also, antioxidant rich Decalepis hamiltonii roots offer protection against OP (dichlorvos)-induced neurotoxicity, as evident from reduced $\mathrm{ChE}$ inhibition. The role of antioxidants is to neutralize the excess of free radicals, to protect the cells against their toxic effects, and to contribute to disease prevention [28].

\section{Conclusions}

Antioxidant rich extracts offer protection against OP (chlorpyrifos)-induced ChE dysfunction. The exact mechanism of prevention is not clear, but could involve the mitigation of oxidative stress. The antioxidant compounds are potential novel nutriceuticals, and need further experimental investigation for their use as therapeutic agents for treating neurotoxicity involving OP-induced ChE dysfunction.

\section{Acknowledgements}

This research was supported by a grant from Walailak University (Biomedical Sciences Research Center WU58508).

\section{References}

[1] TC Marrs. Organophosphate poisoning. Pharmacol. Therapeut. 1993; 58, 51-66.

[2] JE Chambers and PE Levi. Organophosphates, Chemistry, Fate and Effects. Academic Press, San Diego, 1992.

[3] J Bajgar, H Petr, K Jana, S Dasa and K Otakar. Inhibition of Acetylcholinesterase in different structures of the rat brain following soman intoxication pretreated with Huperzine A. Int. J. Mol. Sci. 2007; 8, 1165-76.

[4] T Galloway and Handy R. Immunotoxicity of organophosphorous pesticides. Ecotoxicology 2003; 12, 345-63.

[5] F Worek, M Koller, H Thiermann and L Szinicz. Diagnostic aspects of organophosphate poisoning. Toxicology 2005; 214, 182-9.

[6] D Milatovic, RC Gupta, M Aschner. Anticholinesterase toxicity and oxidative stress. Sci. World J. 2006; 6, 295-310.

[7] K Soltaninejad and M Abdollahi. Current opinion on the science of organophosphate pesticides and toxic stress: A systematic review. Med. Sci. Monit. 2009; 15, 75-90.

[8] A Srivastava and T Shivanandappa. Differential cholinesterase inhibition in the rat brain regions by dichlorvos and protective effect of Decalepis hamiltonii roots. NeuroToxicology 2011; 32, 931-4.

[9] D Bera, D Lahiri and A Nag. Studies on a natural antioxidant for stabilization of edible oil and comparison with synthetic antioxidants. J. Food Eng. 2006; 74, 3. 
http://wjst.wu.ac.th

[10] A Chanawirat, C Toshulkao, P Temcharoen and T Glinsukon. Protective Effect of Thunbergia laurifolia Extract on Ethanol-induced Hepatotoxicity in Mice. Mahidol University, Bangkok, Thailand, 2000.

[11] S Charumanee, S Vejabhikul, Z Taesotikul, W Netsingha, P Sirisaad and P Leelaporn-pisit. Development of Topical Anti-inflammatory Preparations from Thumbergia Laurifolia Linn. Phase 1. Research Report. Chiangmai University, Chiangmai, Thailand, 1998.

[12] J Tangpong and S Satarug. Alleviation of lead poisoning in the brain with aqueous leaf extract of the Thunbergia laurifolia (Linn.). Toxicol. Lett. 2010; 198, 83-8.

[13] S McDonald, PD Prenzler, M Autolovich and K Robards. Phenoliccontent and antioxidant activity of olive extracts. Food Chem. 2001; 73, 73-84.

[14] CA Rice-Evans. NJ Miller and G Paganga. Structure antioxidant activity relationship of flavonoids and phenolic acids. Free Radic. Biol. Med. 1996; 20, 933-56.

[15] S Dan, Z Sujuan, W Yongfeng and Y Lingfang. Antioxidant activity of mangostin in cell free system and its effect on K562 leukemia cell line in photodynamic therapy. Acta Biochim. Biophy. Sicina 2009; 41, 1033-43.

[16] CS Alisi, OA Ojiako, CG Osuagwu and GOC Onyeze. Free radical scavenging and in vitro antioxidant effects of ethanol extract of the medicinal herb Chromolaena odorata linn. British J. Pharmaceut. Res. 2011; 1, 141-55.

[17] GL Ellman, KD Courtney, V Andres and RM Feather-stone. A new and rapid colorimetric determination of acetylcholinesterase activity. Biochem. Pharmacol. 1961; 7, 88-95.

[18] M Moniruzzaman, M Asaduzzaman, MS Hossain, J Sarker, SM Abdur Rahman, M Rashid and MM Rahman. In vitro antioxidant and cholinesterase inhibitory activities of methanolic fruit extract of Phyllanthus acidus. BMC Compl. Altern. Med. 2015; 15, 403.

[19] J Vaya, PA Belinky and M Aviram. Antioxidant constituents from licorice roots: Isolation, structure elucidation and antioxidative capacity toward LDL oxidation. Free Radic. Biol. Med. 1997; 23, 30213.

[20] MR Basha, W Wei, M Brydie, M Razmiafshari and NH Zawia. Lead-induced developmental perturbations in hippocampal Sp1 DNA-binding are prevented by zinc supplementation: In vivo evidence for $\mathrm{Pb}$ and $\mathrm{Zn}$ competition. Int. J. Dev. Neurosci. 2003; 21, 1-12.

[21] H Mohan. Cell Injury and Cellular Adaptations. In: Textbook of Pathology. Jaypee Brothers Medical Publishers, New Delhi, 2010.

[22] PR Sailaja, S Kalva, A Yerramilli and S Mamidi. Free radicals and tissue damage: Role of antioxidants. Free Radic. Antioxid. 2011; 1, 2-7.

[23] M Valko, D Leibfritz, J Moncol, MT Cronin, M Mazur and J Telser. Free radicals and antioxidants in normal physiological functions and human disease. Int. J. Biochem. Cell Biol. 2007; 39, 44-84.

[24] CJ Rickwood and TS Galloway. Acetylcholinesterase inhibition as a biomarker of adverse effect. A study of Mytilus edulis exposed to the priority pollutant chlorfenvinphos. Aquat. Toxicol. 2004; 67, 45-56.

[25] A Ranjbar, P Pasalar and M Abdollahi. Induction of oxidative stress and acetylcholinesterase inhibition in organophosphorous pesticide manufacturing workers. Hum. Exp. Toxicol. 2002; 4, 179-82.

[26] O Lopez, AF Hernandez, L Rodrigo, F Gil, G Pena, JL Serrano, T Parrón, E Villanueva and A Pla. Changes in antioxidant enzymes in humans with long-term exposure to pesticides. Toxicol. Lett. 2007; 171, 146-53.

[27] S Khan and G Koura. Subacute oral toxicity of chlorpyriphos and protective effect of green tea extract. Pest Biochem. Physiol. 2007; 89, 118-23.

[28] LA Pham-Huy, H He and C Pham-Huy. Free radicals, antioxidants in disease and health. Int. J. Biomed. Sci. 2008; 4, 89-96. 